\title{
O PROFESSOR DE CIÊNCIAS DAS ESCOLAS MUNICIPAIS DE RECIFE E SUAS PERSPECTIVAS DE EDUCAÇÃO PERMANENTE
}

\author{
Science teachers from public schools in Recife \\ and their perspective on continuing education
}

Kênio E. C. Lima ${ }^{1}$

Simão D. Vasconcelos ${ }^{2}$

\begin{abstract}
Resumo: Neste artigo, descrevemos uma pesquisa sobre o perfil do professor de Ciências da Rede Municipal de Recife enfatizando suas perspectivas de formação continuada em Biologia. A pesquisa foi realizada por meio de entrevistas estruturadas entre 2001 e 2002, em 31 escolas. Registramos fraca interação entre os professores e a universidade, embora a maioria dos professores tenha interesse em interagir mais, na forma de cursos, capacitações, oficinas, palestras e pós-graduação. Discute-se o papel da universidade pública como pólo gerador de conhecimento e reflexão sobre a educação permanente de professores de Ciências da rede pública.
\end{abstract}

Palavras-chave: Formação continuada. Ensino de Ciências. Universidade. Extensão.

\begin{abstract}
In this article, we describe research about the characterization of Science teachers from public schools in Recife, emphasizing their perspectives on continuing education in Biology. The study was performed using structured interviews between 2001 and 2002, in 31 schools. We detected a weak interaction between teachers and the university, although most teachers are interested in interacting more, through courses, workshops, seminars and postgraduate courses. We discuss the role of the public university as a producer of knowledge and reflect about life long education for Science teachers from public schools.
\end{abstract}

Key words: Continuing education. Science teaching. University. Extension.

\footnotetext{
${ }^{1}$ Mestre em Ensino das Ciências. Professor da rede estadual de ensino de Pernambuco; colaborador do Laboratório de Ensino de Zoologia da Universidade Federal de Pernambuco (UFPE). <keclima@ig.com.br> ${ }^{2}$ Professor Adjunto, PhD, coordenador do Laboratório de Ensino de Zoologia, Departamento de Zoologia, Centro de Ciências Biológicas, Universidade Federal de Pernambuco (UFPE). <simao@ufpe.br>
}

\footnotetext{
2 Laboratório de Ensino de Zoologia, Departamento de Zoologia Centro de Ciências Biológicas UFPE

Av. Prof. Moraes Rego

Recife, PE

347

50.670-420

Ciência $\stackrel{乛}{ }$ Educação, v. 14, n. 2, p. 347-364, 2008
} 


\section{Introdução}

\section{Desafios na formação de professores de Ciências}

Mudanças de paradigmas educacionais exigem do professor de Ciências dinamismo e capacidade para abordar temas cada vez mais complexos e multidisciplinares. Por melhor que seja o curso de Licenciatura, a formação do professor não é suficiente para capacitá-lo diante dos futuros desafios metodológicos, conceituais e de gestão escolar. Recém-formados raramente conseguem enfrentar a disparidade entre o embasamento da graduação e o real da sala de aula, resultante do distanciamento entre o teórico dos livros e propostas pedagógicas e o prático da ação docente, muitas vezes trabalhado em poucas horas nas disciplinas de estágio ou práticas de ensino. Como ressalta Tardif (2002), a formação para o magistério esteve dominada, sobretudo, pelos conhecimentos disciplinares produzidos geralmente numa redoma de vidro, sem conexão com a ação profissional, devendo, em seguida, serem aplicados na prática por meio de estágios ou outras atividades do gênero.

As barreiras para um exercício pleno do magistério incluem, ainda: a fragilidade do material didático, a baixa remuneração, o limitado acesso a fontes atualizadas de informação, e a fraca interação com a comunidade científica. Como resultado, muitos educadores desempenham suas atividades utilizando basicamente os conhecimentos assimilados em sua formação acadêmica formal, minando sua capacidade de produzir mudanças por falta de oportunidade e/ou estímulo. Idealmente, em sua formação profissional, o professor deveria articular seus saberes docentes para a implementação de novas estratégias metodológicas incorporadas na formação acadêmica, aprimoradas por valores assimilados em ambientes não acadêmicos da formação profissional, compondo um "amálgama, mais ou menos coerente, de saberes oriundos da formação profissional e de saberes disciplinares, curriculares e experienciais" (TARDIF, 2002, p. 26).

O abismo entre o conhecimento assimilado na universidade e a realidade da sala de aula tende a aumentar com o tempo e a falta de atualização. Isto porque, naturalmente, o educador enfrenta, em seu oficio diário, provocações diversas que vão desde a simples curiosidade do aluno, com indagações a serem respondidas imediatamente, ao uso de novas tecnologias, como as (ainda) subexploradas facetas da informática na educação. A velocidade da transformação de conceitos, incluindo métodos de trabalho e avaliação do conteúdo, contribui para que a visão de ensino de um professor que não se atualiza torne-se rapidamente obsoleta.

As lacunas na formação teórico-prática de professores de Ciências instigam a oferta de instrumentos que qualifiquem seu trabalho e, conseqüentemente, aprofundem a aprendizagem do aluno. Tais instrumentos têm como função permitir ao professor trabalhar a heterogeneidade de conhecimentos prévios dos alunos, e enfrentar as diversidades associadas a conceitos culturais das comunidades. Neste aspecto, o envolvimento de educadores em pesquisas que se destinam a produzir, adaptar, inovar e testar metodologias e recursos didáticos é indispensável para a própria reconstrução de seu modo de pensar e agir no ensino. 
O professor de Ciências das escolas municipais de Recife ...

\section{Educação permanente como ferramenta de melhoria da qualidade de ensino}

Segundo Rosa e Schnetzler (2003), a formação continuada resulta da necessidade de contínuo aprimoramento profissional e de reflexões sobre a própria prática pedagógica, além da necessidade de superar o distanciamento entre as contribuições da pesquisa educacional e sua utilização em sala de aula. Entretanto, a maioria dos programas de capacitação limita-se a ações de reciclagem, geralmente na forma de cursos de curta duração e oficinas - o que pouco contribui para romper o modelo tradicional de formação docente, e são dirigidas para a aplicação de fórmulas e modelos preconcebidos para enfrentar dificuldades pontuais (ROSA e SCHNETZLER, 2003).

Como ressalta Moreira (2003), a capacitação é algo temporário, enquanto a formação se coloca infinda; porém, não se pode desprezar a qualificação e a contribuição que ambas determinam às melhorias do profissional em educação e do sistema a que pertencem. Embora se reconheça que a formação inicial e a continuada sejam dois momentos complementares da formação do educador,

A formação continuada deve representar uma ruptura com os modelos tradicionais e também representar a capacidade do professor entender o que acontece na sala de aula, identificando interesses significativos no processo de ensino-aprendizagem na própria escola, valorizando e buscando o diálogo com colegas e especialistas (MOREIRA, 2003, p. 130).

Porém, para garantir resultados, precisa-se entender que: "propor cursos de formação continuada, para profissionais que estão em sala de aula, já há algum tempo, requer que olhemos para as reais condições daqueles que vão oferecer e daqueles que vão freqüentar" (VIANNA e CARVALHO, 2000, p. 32); e, ainda, que os objetivos de quem oferece a formação nem sempre correspondem às expectativas do participante, pois este, muitas vezes, busca fórmulas prontas e aplicáveis para a prática exercida em sua sala de aula.

\section{A universidade pública fomenta a educação permanente?}

Por se tratar de pólo consolidado de produção e socialização de conhecimento comprometido com a comunidade, a universidade pública deve assumir papel de referência em pesquisa, divulgação e aplicação de metodologias de educação. Universidades "podem melhorar a formação inicial e continuada dos professores e estes, por sua vez, melhoram e elevam o nível de desempenho de seus alunos, qualificando-os para um melhor e maior rendimento no Ensino Fundamental e Médio" (FRAZZON, 2001, p. 73).

Universidades representam o ambiente ideal para a formação continuada do professor, já que, pela qualidade de sua infra-estrutura e de pessoal, podem disponibilizar: formação complementar e pós-graduação, capacitações, parcerias em projetos de pesquisa, eventos científicos, e outros. Trata-se de um desafio, pois: 
Os docentes das universidades, quando discutem a formação do professor, desvalorizam o patrimônio de experiência e de conhecimento de que dispõem os professores a partir de sua prática, revelando também grande dificuldade em desenvolver trabalho de parceria e de valorização das competências construídas na prática profissional. (DIASDA-SILVA, 1998, p. 2)

Do mesmo modo, é responsabilidade do educador interessado no aprofundamento de suas capacitações: buscar manter contato com instruções de Ensino Superior, fazendo valer seus saberes docentes; dedicar tempo e interesse para priorizar esta parceria; organizarse com os colegas para detectar pontos críticos que necessitam ser aperfeiçoados em seu trabalho diário e, por último, cobrar dos gestores a oferta periódica de oportunidade de qualificação complementar.

\section{Caracterização do problema e dos objetivos da pesquisa}

A cooperação formal entre professores da rede pública e as universidades de Pernambuco tem sido subexplorada por todos os agentes envolvidos. Há uma série de lacunas, no conhecimento sobre a atuação do professor de Ciências, que tolhem uma visão aprofundada da interação escola-universidade. Por exemplo, qual o nível de interação dos professores com as instituições de Ensino Superior (IES) locais? Quais as dificuldades e obstáculos para uma maior interação? Quais áreas do conhecimento científico despertam o interesse de professores de Ciências para uma formação continuada? Que atividades mantidas pelas universidades podem ser exploradas pelo professor do Ensino Básico? A resposta a esses questionamentos pode contribuir para se conhecer a atuação profissional do docente e subsidiar a oferta de atividades extensionistas por parte das IES.

Com base nestas lacunas, o presente trabalho teve como objetivo caracterizar o perfil do professor do Ensino Fundamental da rede municipal do Recife, no que se refere a sua experiência profissional, para mapear suas perspectivas de educação permanente disponibilizada pelas instituições de Ensino Superior locais. Ao entrevistar os professores, buscamos compreender seus anseios e oportunidades, identificando as áreas e atividades prioritárias para futuras ações de educação permanente.

\section{Metodologia}

A pesquisa, caracterizada como um levantamento exploratório descritivo, foi realizada de novembro/2001 a março/2002, tendo como instrumento de coleta de dados entrevistas estruturadas com base em um questionário predefinido (apêndice). As entrevistas foram realizadas com os professores de Ciências do $3^{\circ}$ e $4^{\circ}$ ciclos do Ensino Fundamental das escolas da rede municipal do Recife, PE. As visitas às escolas foram previamente agendadas e autorizadas pelos diretores e conduzidas nos horários de aula, tradicionalmente à tarde e à noite. Foram entrevistados 42 professores de 31 escolas mantidas pela Prefeitura, o que corresponde a $89 \%$ do total de escolas municipais de Recife que trabalham com o Ensino Fundamental. 
O professor de Ciências das escolas municipais de Recife ...

O questionário continha perguntas objetivas e discursivas, possibilitando interação e intervenção por parte dos professores entrevistados, cujas respostas foram categorizadas conforme Bardin (2004). Os contatos foram iniciados com uma breve explanação sobre a natureza da pesquisa, para ressaltar seu caráter integrador e dissipar interpretações errôneas quanto aos objetivos do estudo, evitando ser interpretada como uma "fiscalização". Cada entrevista durou, no máximo, trinta minutos, e o anonimato dos entrevistados foi mantido ao longo do trabalho. Solicitou-se a autorização para se anotarem respostas e comentários, quando pertinente. Para acompanhar as respostas e transcrições, cada professor foi identificado por um número de 1 a 42.

Buscou-se caracterizar o perfil do docente com questões sobre sua formação acadêmica, idade, experiência e formação complementar, aqui definida como: cursos de extensão, participação em eventos científicos, cursos de atualização, seminários, workshops, congressos, simpósios, participações em eventos coordenados pelas universidades locais e cursos de pós-graduação. Objetivou-se também analisar o interesse do professor em atividades de interação na forma de visitas, projetos, assessoria e utilização de coleções didático-científicas. Por fim, buscou-se identificar áreas de interesse para futuras atividades de educação continuada e cursos de pós-graduação, tendo como eixos as áreas de maior dificuldade e de maior interesse para a realização de pesquisas futuras junto às IES. Devido à atuação dos autores deste trabalho, priorizou-se a abordagem de projetos relacionados às Ciências Biológicas ao longo da pesquisa.

\section{Resultados e discussão}

\section{Caracterização do professor de Ciências das escolas municipais de Recife}

De acordo com as entrevistas, observou-se que a faixa etária do professor da rede municipal de Recife caracterizava-se da seguinte forma: 5\% dos professores tinham menos de 25 anos, $26 \%$ entre 26 e 35 anos, $33 \%$ entre 36 e 45 anos, e $36 \%$ tinham idade superior a 45 anos. A maioria (cerca de $60 \%$ ) possuía significativa experiência na docência, ensinando há mais de dez anos (Figura 1).

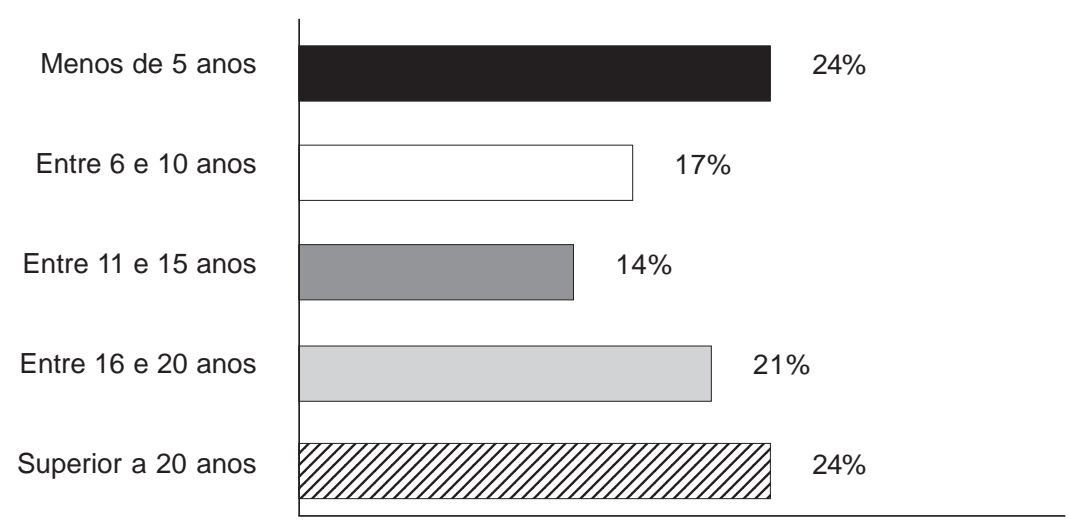

Figura 1. Tempo de serviço no magistério dos professores de Ciências da rede municipal do Recife. 
A escassez de concursos para renovação dos quadros efetivos - na proporção em que a situação atual do Ensino Fundamental demanda - contribui para manter uma gigantesca carência de professores de Ciências no país, especialmente no Nordeste. A ampliação do número de estudantes matriculados no Ensino Fundamental público - significativa conquista da educação brasileira nos últimos anos - não veio acompanhada por um programa de renovação do quadro docente. Limitações orçamentárias e problemas de infra-estrutura também estão entre os principais empecilhos para a contratação de novos professores.

Como conseqüência deste engessamento, alguns sistemas de ensino utilizam professores com contrato temporário e/ou estagiários, dos quais se espera que desempenhem as funções de um professor regular, porém a um custo reduzido. Entre 2004 e 2007, o Governo do Estado de Pernambuco e a Prefeitura de Recife realizaram concursos públicos para substituir parte de seus contratos temporários, executados, muitas vezes, por graduandos. Essas medidas foram aceleradas por pressões do poder público e pelos resultados da duvidosa qualidade de ensino e aprendizagem observados. No entanto, isto não foi suficiente para suprir a demanda, pois ainda realizam contratos temporários com o intuito de se completar o quadro docente.

Se, por um lado, o fato de quase um quarto dos professores lecionarem há mais de vinte anos traz significativos benefícios decorrentes da experiência, por outro pode significar uma defasagem em relação às inovações do conteúdo. No caso de Biologia, foco dessa pesquisa, significativas mudanças conceituais e tecnológicas ocorreram nos últimos vinte anos, as quais não foram necessariamente incorporadas ao cotidiano do professor ou a sua principal ferramenta de atualização, o livro didático.

Conforme esperado, a remuneração dos professores é baixa: 31\% dos entrevistados recebem até três salários-mínimos; $57 \%$ recebem de quatro a oito e $10 \%$ recebem de nove a doze (valor do salário-mínimo em 2003: $\mathrm{R} \$ 180,00)$. Somente um professor recebe mais de 12 salários-mínimos, assumindo a carga horária máxima, acrescida de outras atividades além do magistério. Os professores de melhor remuneração trabalham nos três turnos, acrescidos de gratificações, além de atividades não correlatas ao ensino. Freqüentemente, os educadores trabalham em outras instituições, como escolas particulares, e, em alguns casos, até em hospitais (dois entrevistados) e clínicas veterinárias (um entrevistado). Tal acúmulo de carga horária foi apontado como o único recurso que lhes permite o suprimento das necessidades básicas, como pagamento de aluguel, atualização bibliográfica e educação dos filhos, conforme comentários dos professores. Comumente, a carga horária dos professores é variável conforme o contrato, de $150 \mathrm{~h} / \mathrm{a}$ a $350 \mathrm{~h} / \mathrm{a}$ mensais, que devem suprir as atividades de sala de aula, elaboração e correção de avaliações, tempo insuficiente para alguns ainda realizarem novos estudos e aperfeiçoamentos conceituais e metodológicos.

"Não há a menor condição de sustentar toda a família com o salário que ganho da prefeitura. Trabalho em três escolas, entre públicas e particulares, quase que nos três turnos, e mesmo assim tenho a sensação que meu trabalho não é compensado, nem reconbecido, financeiramente”. (Professor 13)

As peculiaridades desta profissão-vocação fazem do educador uma categoria de servidor com propósitos sociais diferenciados, afinal, ele "não trabalha apenas um 'objeto', ele trabalha com sujeitos e em função de um projeto: transformar os alunos, educá-los e 
O professor de Ciências das escolas municipais de Recife ...

instruí-los" (TARDIF, 2002, p. 13), sendo necessário um reconhecimento além do âmbito meramente financeiro. Além do limitado reconhecimento profissional, professores das redes municipais das regiões Norte e Nordeste do país precisam ainda superar disparidades salariais, destacadas por Akkari (2001):

Os salários dos docentes são outro indício de disparidade entre as redes. Com exceção das escolas federais, pouco numerosas, os salários dos docentes da rede pública são nitidamente inferiores aos da rede privada. A diferença mais substancial está entre escolas municipais do Nordeste e as escolas particulares do Sudeste. Os docentes, nestas ultimas ganham cinco vezes mais que os professores que trabalham nas primeiras. (AKKARI, 2001, p. 170)

Educadores necessitam estar constantemente atualizados para explorar os saberes e promover novas aprendizagens dos alunos. Neste estudo, os professores declaram utilizar livros-texto - além dos didáticos, adotados pela rede de ensino - como fontes para a atualização e reformulação de conceitos. Contudo, a dificuldade em obter maiores e melhores acervos pessoais e na biblioteca da escola foi ressaltada por $43 \%$ dos entrevistados. Como empecilhos para uma atualização teórica sobre conteúdos de Ciências, 67\% destacam a falta de tempo, $17 \%$ citam a ausência de bons textos científicos em Português, e 16\%, a escassez de bibliotecas especializadas. Em estudo recente, Lima e Vasconcelos (2006) relatam que 65\% dos professores de Ciências da rede municipal afirmam estar satisfeitos com o livro didático adotado, o que pode explicar parcialmente a fraca procura por outras fontes de informação.

Outro dado observado é que boa parte das escolas ofereciam acesso à internet $(64,5 \%$ das instituições visitadas), embora apenas dois professores (4,8\%) afirmassem utilizar esta ferramenta para se informar sobre congressos, eventos, e outras oportunidades de atualização. Para a maioria dos professores, o acesso à internet acontece em suas residências, com freqüência quase que diária. Entretanto, com base nas respostas sobre o uso destinado a pesquisas a serem aplicadas em sua prática pedagógica, infere-se que o uso da internet para atualização sobre conteúdos científicos encontra-se ainda subestimado.

\section{Interação com as universidades públicas locais}

A maioria dos professores interage pouco com as universidades locais; 40,4\% dos entrevistados não chegam a manter qualquer tipo de contato, categoria seguida por professores que mantêm visitas e atividades esporádicas (Tabela 1). A principal causa da fraca interação seria a falta de tempo, justificativa alegada por mais de $60,0 \%$ dos entrevistados, que afirmam precisar complementar o salário com outras atividades, confirmada por um dos depoimentos dos professores: "Trabalho pelo menos dez horas por dia. No meu caso, ainda trabalho como enfermeira para completar o salário. Bem que en gostaria de interagir mais com as faculdades, mas o problema mesmo é o tempo" (Professora 1). 
Lima, K. E. C.; Vasconcelos, S. D.

Tabela 1. Freqüência anual de interação entre professores de Ciências da rede municipal de ensino de Recife e universidades públicas de Recife.

\begin{tabular}{lcc}
\hline \multicolumn{1}{c}{ Categorização } & N & $\%$ \\
\hline $\begin{array}{l}\text { Não tem interação com a UFPE por falta de tempo. } \\
\text { A interação com a UFPE é muito pouca, chegando a ser uma vez por ano, quando participa } \\
\text { de evento que interessa. }\end{array}$ & 17 & 40,0 \\
$\begin{array}{l}\text { Busca participar de eventos gratuitos ou pagos promovidos pela UFPE, o que equivale a, } \\
\text { mais ou menos, duas vezes ao ano. }\end{array}$ & 7 & 17,0 \\
$\begin{array}{l}\text { Interações mais constantes por participar de eventos, pesquisas e cursos de } \\
\text { Pós-Graduação. }\end{array}$ & 8 & 19,0 \\
\hline
\end{tabular}

Os professores alegaram ainda desconhecer atividades extensionistas mantidas pelas universidades, possivelmente uma conseqüência da fraca divulgação das ações universitárias, especialmente as públicas, junto às instituições de Ensino Fundamental e Médio: "Estudei em faculdade particular. Para falar a verdade, nunca mais voltei a minha faculdade depois que me formei, e nem sabia que as universidades públicas tinham esses eventos de capacitação gratuitos para professores” (Professor 24).

Porém, mesmo com todas as dificuldades, 92,9\% dos entrevistados afirmam que desejam aumentar ou iniciar uma interação com a Universidade Federal de Pernambuco, centro de referência em pesquisa e ensino no Nordeste. Esta busca por conhecimento complementar decorre, em grande parte, das dificuldades conceituais e práticas para se trabalhar determinados conteúdos (Tabela 2), conforme revelado em depoimentos: "Tenho certa dificuldade em trabalhar os conceitos de Física e Química na $8^{a}$ série. Não tive disciplinas na graduação que trabalhassem os conceitos, muito menos atividades práticas, o que me faz sempre recorrer aos livros didáticos e a alguns colegas da área para tirar dívidas" (Professora 41).

Tabela 2. Assuntos abordados no Ensino Fundamental (5a. a $8^{\mathrm{a}}$. séries) que oferecem maiores dificuldades teóricas e metodológicas para os professores da rede municipal de ensino de Recife.

\begin{tabular}{lcc}
\hline \multicolumn{1}{c}{ Categorização } & No $^{\circ}$ & $\%$ \\
\hline Noções de Física & 16 & 38,0 \\
Noções de Química & 10 & 24,0 \\
Corpo Humano (Reprodução / Anatomia / Fisiologia) & 9 & 21,0 \\
Meio Ambiente (Ar, Água, solo) & 5 & 12,0 \\
Outros & 4 & 10,0 \\
Não sente dificuldades & 1 & 2,0 \\
\hline
\end{tabular}

Quando questionados sobre quais atividades e recursos mantidos pelas universidades públicas locais seriam mais úteis a sua atualização profissional, os itens "cursos e palestras" e "disponibilização de laboratórios" foram citados por 83,4\% dos entrevistados, dentre outras atividades (Tabela 3). Isto demonstra a consciência da necessidade de utilização do laboratório como palco de experiências de aprendizagem prática, um recurso ainda inacessível para boa parte dos professores. Outras atividades citadas pelos professores incluíram: cursos de pós- 
O professor de Ciências das escolas municipais de Recife ...

graduação, intercâmbios culturais e capacitações, especialmente sobre Feiras de Ciências. O desejo de aprofundar conhecimentos é inerente à docência, uma vez que:

A construção de professores críticos e reflexivos, de intelectuais engajados e capacitados para a construção da cidadania na sala de aula é desafio emergente em qualquer tentativa conseqüente de transformação da escola. Favorecer, incentivar, estudar e/ou provocar as condições para que este desenvolvimento ocorra, capacitando os professores para enfrentar estes desafios, é tarefa a que a universidade não pode (mais) se furtar. (DIAS-DA-SILVA, 1998, p. 6-7)

Tabela 3. Recursos e atividades mantidas pelas universidades públicas locais que despertam maior interesse aos professores para uma interação na forma de educação permanente (mais de uma opção possível).

\begin{tabular}{lrr}
\hline Categorização & N & $\%$ \\
\hline Cursos / Palestras / congressos & 35 & 83,0 \\
Laboratórios (treinamento em equipamentos, aulas práticas, etc.) & 35 & 83,0 \\
Experimentotecas para observação de fenômenos (ex.: comportamento animal) & 29 & 69,0 \\
Coleções didáticas de Zoologia e Botânica & 27 & 64,0 \\
\hline
\end{tabular}

A importância dada aos laboratórios de Ciências para aulas práticas é recorrente por ser um dos maiores problemas de infra-estrutura em escolas públicas brasileiras, especialmente no Nordeste. Mais do que dispor de laboratório, no entanto, é preciso saber utilizá-lo em toda sua potencialidade. Por exemplo, pesquisa conduzida em escolas públicas de Bauru (SP) revelou que apenas 27,0\% dos professores entrevistados desenvolviam atividades de laboratório, mesmo que esse recurso estivesse disponível em 61,5\% das escolas visitadas (MOURA e VALLE, 2001). Esse espaço físico, aplicado com planejamento e estratégia ainda é vital para o processo de ensino-aprendizagem, tendo sua relevância destacada por Krasilchik (2004):

As aulas de laboratório têm um lugar insubstituível nos cursos de Biologia, pois desempenham funções únicas: permitem que os alunos tenham contato direto com os fenômenos, manipulando os materiais e equipamentos e observando organismos. $\mathrm{Na}$ análise do processo biológico, verificam concretamente o significado da variabilidade individual e a necessidade de se trabalhar sempre com grupos de indivíduos para obter resultados não previstos, cuja interpretação desafia sua imaginação e raciocínio. (KRASILCHIK, 2004, p. 86)

A relevância de atividades experimentais no ensino de Biologia pressupõe que os professores as realizem tendo consciência de sua função. Por exemplo, pesquisa recente conduzida entre professores de Ciências de Londrina (PR) revelou que há percepções variadas sobre a prática da experimentação no ensino: 
Perguntas sobre a função e a importância da experimentação na ciência levam a três tipos básicos de respostas: as de cunho epistemológico, que assumem que a experimentação serve para "comprovar a teoria", revelando a visão tradicional de ciências; as de cunho cognitivo, que supõem que as atividades experimentais podem "facilitar a compreensão do conteúdo"; e as de cunho motivacional, que acreditam que as aulas práticas ajudam a "despertar a curiosidade" ou o “interesse pelo estudo” no aluno. (ARRUDA e LABURÚ, 1998, p. 55)

Em relação à formação profissional complementar, 35,7\% dos entrevistados já possuem algum curso de pós-graduação, sendo a maioria $(88,1 \%)$ com o nível de especialização lato sensu. É interessante destacar que $69,0 \%$ dos que ainda não têm pós-graduação pretendem realizá-la, e os motivos para isto incluem o aperfeiçoamento profissional por meio do aumento do conhecimento (citado por 83,0\% dos entrevistados) e melhor remuneração ( $69,0 \%$ ). Lordêlo e Verhine (2001) destacam o valor intelectual adquirido em cursos de pós-graduação, tendo em vista que o retorno se faz em médio prazo, retratando os benefícios destinados à formação do alunado e à instituição a que pertence.

Quando indagados sobre em que área da Biologia desejariam cursar pós-graduação, as áreas de Ecologia e Zoologia apresentaram-se como as mais atrativas (Tabela 4). Tal preferência não surpreende, ao se considerar a tendência mundial em aprofundar o debate sobre temas relacionados ao uso sustentável da natureza e à preservação ambiental, incluindo a busca de soluções para os problemas decorrentes da atividade humana. Estes tópicos têm recebido atenção cada vez maior da mídia, despertando curiosidade da sociedade. Nesta questão, diversos professores demonstraram interesse em contactar tanto a UFPE como a UFRPE (Universidade Federal Rural de Pernambuco, citada espontaneamente por 9,5\% dos entrevistados), que também oferece cursos de especialização e mestrado nestas áreas. Embora outras instituições de ensino superior locais ofereçam pós-graduação lato sensu em áreas de Educação e Biologia (ou sua interface), nenhuma delas foi citada pelos entrevistados. Isto talvez reflita a menor visibilidade das instituições de ensino comunitárias e particulares de Pernambuco, e o maior investimento financeiro necessário para vincular-se a elas, quando comparadas às universidades federais.

Ao oferecer espaço para manifestação de seus anseios, esta pesquisa acabou por despertar o debate sobre um ponto não contemplado nas opções de resposta, mas citado pela maioria dos entrevistados. Referimo-nos ao interesse dos educadores em participar de cursos de formação continuada que abordassem, em vez de conteúdo "técnico", aspectos de gestão de sala de aula e motivação de alunos. Isto porque, dos 42 professores entrevistados, $38(90,5 \%)$ destacaram, como pontos frustrantes de seu desempenho, a "falta de estratégias, ferramentas, conhecimento ou técnicas", segundo suas palavras, para lidar com dois problemas graves e crescentes no universo da escola pública: a falta de interesse e de disciplina dos alunos. O desabafo de um dos professores ilustra a questão:

"É sempre válido aprender sobre novos conteúdos, mas acho que preciso aprender técnicas para lidar com alunos indisciplinados e desinteressados. Isto é tão ruim quanto a baixa remuneração: lidar com alunos que não prestam atenção, não têm senso de bierarquia ou respeito pela figura do professor. [...] Se a universidade tivesse um curso sobre isso, en me esforçaria para participar". (Professor 24) 
O professor de Ciências das escolas municipais de Recife ...

Tabela 4. Áreas da Biologia que despertam mais interesse aos professores de Ciências da Rede Municipal de Ensino de Recife, para possível Pós-Graduação (mais de uma opção possível).

\begin{tabular}{lcc}
\hline \multicolumn{1}{c}{ Categorização } & N & \% \\
\hline Ecologia (educação ambiental, conservação) & 22 & $52,0 \%$ \\
Zoologia (taxonomia, fisiologia, anatomia comparada) & 16 & 38,0 \\
Microbiologia (microrganismos patogênicos, relação com o ser humano e com o ambiente) & 14 & 33,0 \\
Genética (biotecnologia, clonagem, transgenia, melhoramento genético) & 12 & 29,0 \\
Saúde humana (endemia, vetores, controle de epidemias) & 11 & 24,0 \\
\hline
\end{tabular}

\section{O papel das universidades públicas na educação permanente de professores de Ciências}

De acordo com os Parâmetros Curriculares Nacionais, o ensino de Biologia deve abordar temas contemporâneos, com a finalidade de fortalecer as relações entre Ciências, Tecnologia e Sociedade. Esta abordagem exige dos professores a capacidade de perceber "Ciências" nas diversas manifestações do cotidiano, e de trazê-la para o dia-a-dia dos estudantes, para promover a contextualização dos conteúdos. Porém, como exigir dos professores recém-formados a habilidade para utilizar, criar e adaptar estratégias educativas se os próprios cursos de Licenciatura deixam a desejar neste aspecto?

Recentemente, os cursos de Licenciatura em Ciências (incluindo Biologia na UFPE) passaram por profundas transformações, em parte para atender a exigências do Ministério da Educação. Espera-se que a nova estrutura curricular habilite o docente dentro de um contexto mais amplo, com uma formação mais humanista, contemplando disciplinas e tópicos como Sociologia, Economia e Gestão Escolar, conduzindo-os a novas competências que refutem compreensões simplistas, desconectadas da realidade a que pertencem, pois, "os programas de formação não devem buscar conhecimentos técnicos sem fomentar competências em métodos e relações humanas" (DEPRESBITERIS, 2004, p. 12).

Embora as respostas dos professores possam sugerir indiferença das universidades em relação à formação complementar, ressalta-se, a título de exemplo, que a UFPE oferece regularmente atividades de extensão voltadas para professores de Ciências. Somente no período 2000-2003, foram oferecidas, pelo Centro de Ciências Biológicas, 18 ações de extensão entre cursos e projetos - voltadas exclusivamente para a área de Educação, a maioria gratuita e com certificação (SILVA e VASCONCELOS, 2006). São disponibilizados laboratórios e auditórios da universidade para palestras e cursos de curta duração, contribuindo para minimizar fragilidades da educação formal, com divulgação em locais estratégicos e pela internet, em sites permanentes, mantidos pela extensão do Centro de Ciências Biológicas.

Questionados sobre a participação em eventos mais específicos e aprofundados, como congressos, simpósios e workshops, os docentes ressaltam as dificuldades como custos e falta de tempo, pois muitos apresentam mais de um vínculo empregatício, além do desconhecimento da divulgação, conforme comentário: "Sei de alguns colegas que participaram destes eventos cientificos [congressos] com a ajuda da prefeitura; mas fico sabendo próximo do evento, não sendo possivel me programar, pois tenho filhos e esposo" (Professora 2). 


\section{Considerações finais e perspectivas}

A pesquisa aponta uma série de "gargalos" na construção de uma relação contínua, direta, bidirecional entre o professor de Ciências e a instituição formadora de docentes. Com base neste painel de posicionamentos, proposições e inquietações, alguns obstáculos são apontados com maior intensidade pelos docentes, e merecem ser explorados - até para sua possível desmistificação.

\section{Limitada oferta de ações de educação continuada}

Universidades locais oferecem uma variedade de palestras, cursos de curta duração, e ações de extensão com foco na preparação de futuros professores, e na atualização dos que estão em atividade, buscando promover situações de aprendizagens alicerçadas em sólido embasamento científico. Mesmo que ainda sejam iniciativas pontuais, a provocação, o convite, a oferta consciente do desejo que os docentes possuem, aos poucos, estão trazendo educadores do Ensino Básico para as salas de aula, auditórios, laboratório, discutindo e re-imaginando sua prática pedagógica.

A universidade pode auxiliar no diagnóstico da realidade escolar, detectar deficiências, propor sugestões e - em parceria com as instituições pertinentes - oferecer atividades de formação permanente. Iniciativas de aproximação, embora tímidas, se intensificam. Recentemente, por exemplo, a Secretaria Municipal de Educação do Recife contou com docentes e infra-estrutura da UFPE em projeto de parceria para formação continuada de seus professores de Ciências. Iniciativas neste sentido devem contornar as fragilidades nos cursos da formação de docentes, como as assinaladas por Teixeira e Vale (2001):

As metodologias utilizadas e demais processos pedagógicos desenvolvidos nos cursos de graduação são essencialmente tradicionais e há resistência às mudanças que muitas vezes são exigidas dos graduandos (licenciados) quando estes começam a trabalhar no magistério. [...] Os cursos de reciclagem e/ou formação continuada acontecem com baixa freqüência e, na maioria das vezes, dão pouca atenção à formação geral do educador, preocupando-se via de regra com os conteúdos específicos de área. (TEIXEIRA e VALE, 2001, p. 34)

A Universidade Federal de Pernambuco vem abrindo suas portas a docentes do Ensino Básico para ações educativas e científicas que se destinam a minimizar defasagens na sua formação e atualização. Visitas e intercâmbios possibilitam ao educador re-experienciar uma realidade que fez parte de sua formação, por meio de cursos de extensão, palestras, eventos e oficinas oferecidas pela instituição, além de cursos de pós-graduação - especialização, mestrado e doutorado (SILVA e VASCONCELOS, 2006). Em eventos extensionistas, a UFPE propicia oportunidades para profissionais conhecerem as inovações do conhecimento científico, sobretudo por meio da oferta de eventos e cursos de curta duração. 
O professor de Ciências das escolas municipais de Recife ...

\section{Baixo nível de conhecimento dos professores de Ciências}

Seria então válido afirmar que nossos professores de Ciências estão pouco interessados em discutir e se posicionar diante dos avanços conceituais? Embora não podendo isentar o professor da responsabilidade por suas defasagens, é oportuno lembrar que falta maior apoio das políticas que vinculam as instituições públicas da região aos projetos de formação continuada. Enquanto não houver mudanças de políticas públicas de incentivo, as limitações intelectuais e orgânicas dos professores comprometerão ainda mais a qualidade do ensino público, pois a sobrecarga de trabalho, aliada a uma remuneração precária, amplia os argumentos de que não vale a pena se qualificar por não haver o reconhecimento esperado.

Se não houver o reconhecimento da real necessidade de aperfeiçoamento continuado dos educadores do Ensino Básico em universidades, as interações funcionarão como intercâmbios isolados, por iniciativas dos poucos que conseguem se ausentar de suas rotinas. Em nosso estudo, detectamos motivações em relatos de professores: '[...] sabendo que existem eventos [palestras, exposições etc.] promovidos pelas universidades públicas daqui, buscarei me programar para participar destas atividades, pois acho importante para mim. É uma forma de me atualizar e manter contato com estudiosos destas áreas que en gosto" (Professora 1).

Estímulos aos professores são necessários, envolvendo as diversas IES locais. Por exemplo, poderia ser instituído um intercâmbio onde os professores da rede pública participariam de programas de educação permanente e parte de suas atividades didáticas seria desempenhada - com a devida orientação - por licenciandos das instituições federais. Assim, a Educação Básica não ficaria desprovida de professores, que por sua vez estariam investindo em seu aperfeiçoamento profissional, sem comprometimento das atividades na instituição. Já os licenciandos em Ciências realizariam seu estágio curricular, buscando aperfeiçoamento profissional qualitativo, permanecendo maior tempo em sala de aula no período de sua formação básica, adquirindo experiência in loco e atendendo, inclusive, a uma exigência da LDB para a formação de professores.

\section{Dificuldades inerentes em participar de educação continuada}

É certo que a rede pública não disponibiliza professores substitutos em quantidade suficiente para suprir todos os docentes que se proponham a realizar uma formação continuada mais duradoura. Da mesma forma, muitos educadores desempenham atividades paralelas, impossibilitando reuni-los para realizar cursos de aperfeiçoamento e/ou pós-graduação. Sugere-se, à rede pública, reservar parte da carga horária dos docentes para ações interativas com universidades, centros de pesquisa e comunidades circunvizinhas em ações extensionistas.

Neste contexto, a Prefeitura da Cidade do Recife vem estimulando a participação em eventos científicos, tais como a Reunião Anual da Sociedade Brasileira para o Progresso da Ciência (SBPC) e EREBIO (Encontro Regional de Ensino de Biologia). A Secretaria de Educação do Estado de Pernambuco também tem investido na formação continuada de seus professores por meio de capacitações, oficinas, e cursos, além de incentivar a pós-graduação. Um exemplo recente é a parceria com as IES locais para promoção de cursos de especialização em Ciências, gratuitos para os professores do Ensino Básico público. Entretanto, o ritmo da atualização dos professores não acompanha a evolução do conhecimento cientifico e o 
surgimento de novas ferramentas educacionais, tendo em vista as próprias dificuldades conceituais e metodológicas mencionadas pelos entrevistados. Estas iniciativas são ainda insuficientes para gerar resultados concretos, ampliando a defasagem e fraca qualificação do ensino das ciências nas escolas públicas locais.

\section{Conclusões}

Esta pesquisa traça um painel da percepção e interesse dos professores de Ciências em interagir com os centros de produção e disseminação do conhecimento pedagógico básico e aplicado. Muitas vezes, a formação deficiente dos professores, associada à fragilidade do material didático, da metodologia e dos processos avaliativos adotados pelo educador e sugeridos pela instituição, compromete o ensino público, ensino este que foi considerado, durante décadas, como referência em educação. Hoje, baixos investimentos, desvalorização do magistério e declínio do interesse e dedicação dos alunos deflagram vertiginosa queda na formação e aperfeiçoamento dos estudantes, como também um desestímulo ao docente em exercício.

A promoção de atividades práticas de laboratório para aprimoramento de técnicas e conceitos trabalhados com os alunos deve ser incentivada, como também a construção de práticas condizentes com as condições estruturais e financeiras da instituição. É indispensável, também, conceder tempo para o estudo, a leitura, e o acesso a novas fontes de informação que possibilitem a atualização intelectual e o constante aprimoramento de técnicas de ensino.

Há uma percepção dos professores sobre a necessidade da educação continuada. Este é o ponto de partida para desencadear um processo de retorno à sala de aula e ao laboratório, apoiado pelas universidades, para atualização de conceitos e métodos. Em médio prazo, mudanças substanciais na formação básica dos alunos refletirão de forma concreta no nível superior. Sem cursos de aperfeiçoamentos que possibilitem ao educador experimentar o novo, este continuará se valendo, muitas vezes, da cópia de um livro, sem abordagem pessoal e sem visão crítica dos temas contemporâneos, inviabilizando o almejado Ensino Básico público de qualidade.

\section{Agradecimentos}

Agradecemos aos professores da rede municipal de ensino de Recife, pela disponibilidade em compartilhar idéias e expectativas, e às autoridades responsáveis das escolas municipais, pela autorização para se realizar a pesquisa. 
O professor de Ciências das escolas municipais de Recife ...

\section{Referências}

AKKARI, A. J. Desigualdades educativas estruturais no Brasil: entre Estado, privatização e descentralização. Educação \& Sociedade, Campinas, v. 22, n. 74, p. 163-189, 2001.

ARRUDA, S. M.; LABURÚ, C. E. Considerações sobre a função do experimento no ensino de ciências. In: NARDI, R. (Ed.). Questões atuais no ensino de Ciências. São Paulo: Escrituras, 1998. v. 2. p. 53-60.

BARDIN, L. Análise de conteúdo. Trad. Luiz Antero Reto e Augusto Pinheiro. 3. ed. Lisboa: Ed. 70, 2004.

DEPRESBITERIS, L. Instrumentos y técnicas de evolución de impactos y de aprendizaje en programas educativos de capacitación laboral: la necesidad de conjugación. Estudos em Avaliação Educacional, São Paulo, n. 29, p. 5-48, 2004.

DIAS-DA-SILVA, M. H. G. F. O professor e seu desenvolvimento profissional: superando a concepção do algoz incompetente. Caderno CEDES, Campinas, v. 19, n. 44, p. 33-45, 1998.

FRAZZON, L. M. O compromisso da Universidade com a formação continuada do professor. Revista Roteiro, Joaçaba, v. 26, n. 46, p. 81-91, 2001.

GATTI, B. A. A formação dos docentes: o confronto necessário professor x academia. Cadernos de Pesquisa, São Paulo, n. 81, p. 70-74, 1992.

KRASILCHIK, M. Prática de ensino de Biologia. 4. ed. São Paulo: Ed. Edusp, 2004.

LIMA, K. E. C.; VASCONCELOS, S. D. Análise da metodologia do ensino de Ciências nas escolas da rede municipal de Recife. Ensaio: Avaliação e Políticas Públicas em Educação, Rio de Janeiro, v. 14, n. 52, p. 397-412, 2006.

LORDÊLO, J. A.; VERHINE, R. E. O retorno do investimento em mestrado e doutorado para professores universitários: uma avaliação econômica da educação pós-graduada. Estudos em Avaliação Educacional, São Paulo, n. 24, p. 165-186, 2001.

MOREIRA, H. A formação continuada do professor: as limitações dos modelos atuais. Comunicações, Piracicaba, v. 1, p. 123-133, 2003.

MOURA, G. R. S.; VALE, J. M. F. O ensino de Ciências na $5^{a}$ e na $6^{a}$ séries da Escola Fundamental. In: NARDI, R. (Ed.). Educação em Ciências: da pesquisa à prática docente. São Paulo: Escrituras, 2001. n. 3. p. 135-143.

ROSA, M. I. F. P. S.; SCHNETZLER, R. P. A investigação-ação na formação continuada de professores de Ciências. Ciência e Educação, Bauru, v. 9, n. 1, p. 27-39, 2003.

SILVA, M. S.; VASCONCELOS, S. D. Extensão universitária e formação profissional em Biologia: avaliação da experiência da Universidade Federal de Pernambuco. Estudos em Avaliação Educacional, São Paulo, v. 33, n. 17, p. 119-135, 2006.

TARDIF, M. Saberes docentes e formação profissional. 2. ed. Petrópolis: Vozes, 2002. 
Lima, K. E. C.; Vasconcelos, S. D.

TEIXEIRA, P. M. M.; VALE, J. M. F. Ensino de Biologia e cidadania: problemas que envolvem a prática pedagógica de educadores. In: NARDI, R. (Ed.). Educação em Ciência: da pesquisa à prática docente. São Paulo: Escrituras, 2001. n. 3. p. 23-40.

VIANNA, D. M.; CARVALHO, A. M. P. Formação permanente: a necessidade da interação entre a ciência dos cientistas e a ciência da sala de aula. Ciência $\boldsymbol{\&}$ Educação, Bauru, v. 6, n. 1, p. 31-42, 2000.

Artigo recebido em outubro de 2005 e aprovado em março de 2008. 
O professor de Ciências das escolas municipais de Recife ...

APÊNDICE - Roteiro para entrevista: Professor de Ciências x Educação Continuada

\section{I - SOBRE O PROFESSOR:}

1. Sexo: ( ) M ( ) F

2. Instituição de ensino:

$N^{\circ}$ do Professor :

3. Idade: ( ) até 25 anos ( ) 26 a 35 anos ( ) 36 a 45 anos ( ) $>45$ anos.

4. Formação acadêmica: ( ) Ensino médio （ ) Superior. Instituição, curso e ano de graduação:

5. Há quantos anos ensina Ciências? ( ) até $5 \quad\left(\begin{array}{llll}\text { ) 6-10 } & \text { ( ) 11-15 } & \text { ( ) 16-20 } & \text { ( ) }>20\end{array}\right.$

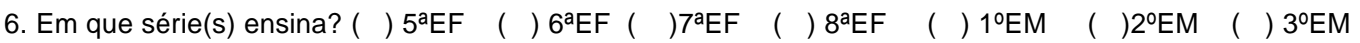

6. Salário mensal (somente com ensino) SM = Salários-Mínimos:

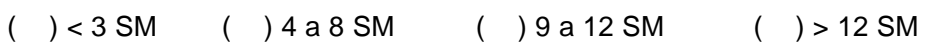

7. Ensina em mais de uma escola? ( ) não （） sim, só pública （ ) sim, pública + particular

8. Tem fonte de renda adicional (não relativa a ensino)? ( ) sim $\quad(\quad)$ não

\section{II - SOBRE FONTES DE INFORMAÇÃO EM CIÊNCIAS}

1. Costuma freqüentar bibliotecas para se atualizar / tirar dúvidas em Ciências? （） sim （ ) não

2. Tem acesso à Internet? ( ) sim （）não. Onde? ( ) casa （）escola （） outros:

3. Utiliza a Internet para elaborar aulas ou pesquisar sobre Ciências? ( ) sim ( ) não. Por quê?

4. Costuma participar de congresso/encontros de Ciências/Educação? ( ) sim （ ) não. Por quê?

5. Sente dificuldade em encontrar material didático sobre biologia? （ ） sim （ ） não

Quais? ( ) custo dos livros ( ) ausência de biblioteca especializada ( ) falta de livrarias técnicas ( ) falta de tempo ( ) ausência de bons textos em português （ ) Outros:

6. Que assunto de Biologia você tem mais dificuldade para ensinar? Por quê?

III-SOBRE OAPERFEIÇOAMENTO PROFISSIONAL

1. Possui alguma pós-graduação? ( ) não （ ) sim. Qual?

2. A escola (prefeitura) oferece algum incentivo à pós-graduação? ( ) não ( ) sim. Qual?

3. Com que freqüência interage com as universidades locais (visitas científicas, cursos de extensão, experimentos com os alunos, congressos etc.)? Justifique: 
Lima, K. E. C.; Vasconcelos, S. D.

4. Você estaria disposto a interagir mais com as universidades locais? Justifique.

5. Pretende fazer algum curso de Pós-Graduação? ( ) sim （ ) não. Por quê?

6. Que atividade / recurso mantido nas universidades locais seria mais útil ao professor de Ciências? (pode citar mais de um)

7. Você faria algum curso de PG caso não houvesse ônus? ( ) não( ) sim. Em que área? (pode citar mais de um)

8. Comentários adicionais. 